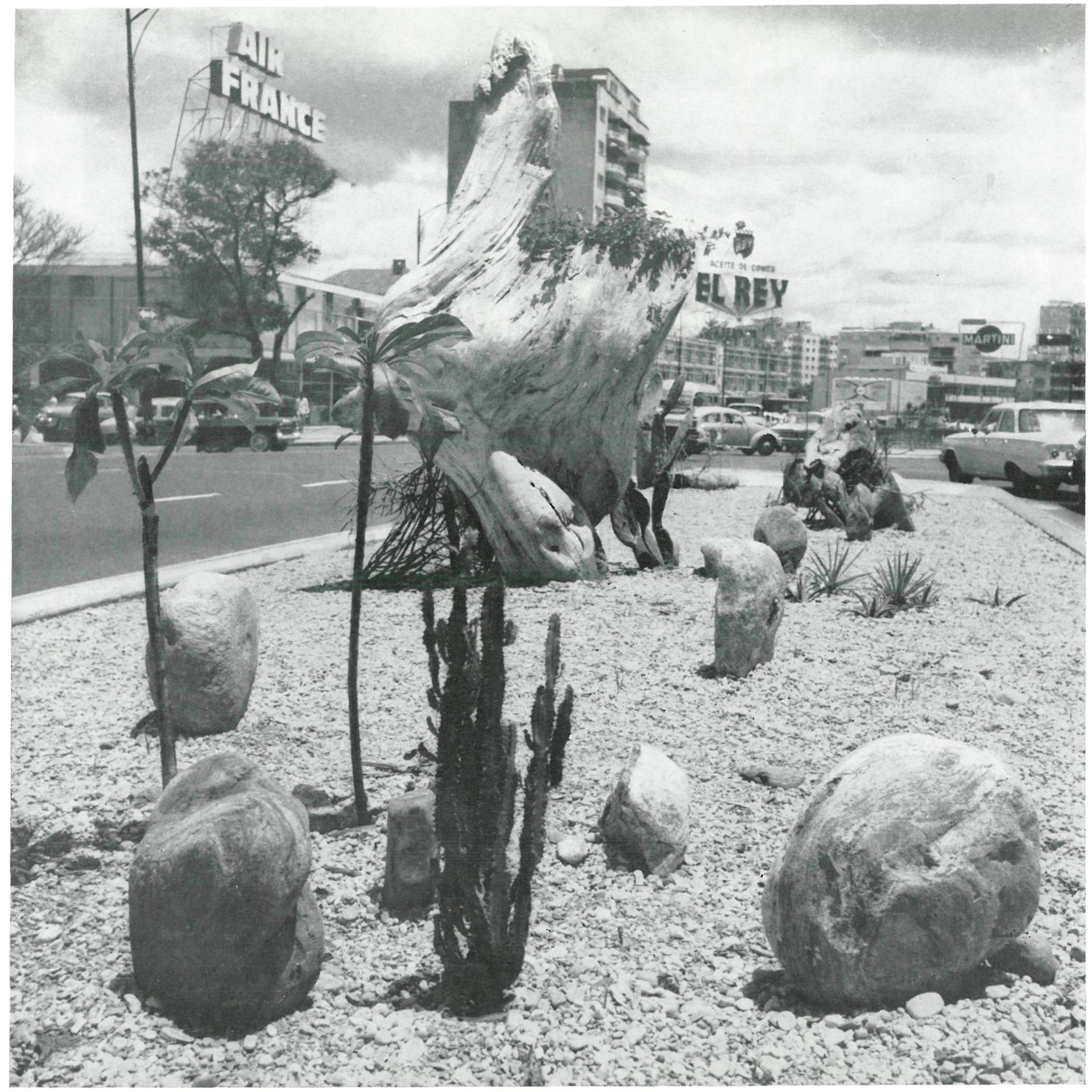

\title{
jardines xerófilos venezolands
}

EDUARDO ROBLES PIQUER, arquitecto-paisajista

$155-2$

\section{simopsis}

Este tipo de jardines - a base de plantas «xerófilas», propias de ambientes secos, en las que la evaporación de agua vegetal es mínima y, como consecuencia, la necesidad de riego o de lluvia es insignificante- resulta sumamente apropiado para lugares como Caracas y otros aún más áridos, en los cuales el período de sequía se prolonga durante bastantes meses del año.

Como una de las características de estos jardines es la ausencia de césped, el tipo suelto y arenoso se utiliza como fondo de la composición del jardín, recubriéndolo con piedras blancas de río o de mar y, a veces, con arena limpia.

Las diferentes alturas de las plantas, superficies y colores, y la integración al conjunto de elementos minerales - cantos rodados - y vegetales - troncos, etc.-, contribuyen a realzar la belleza de estos jardines. 


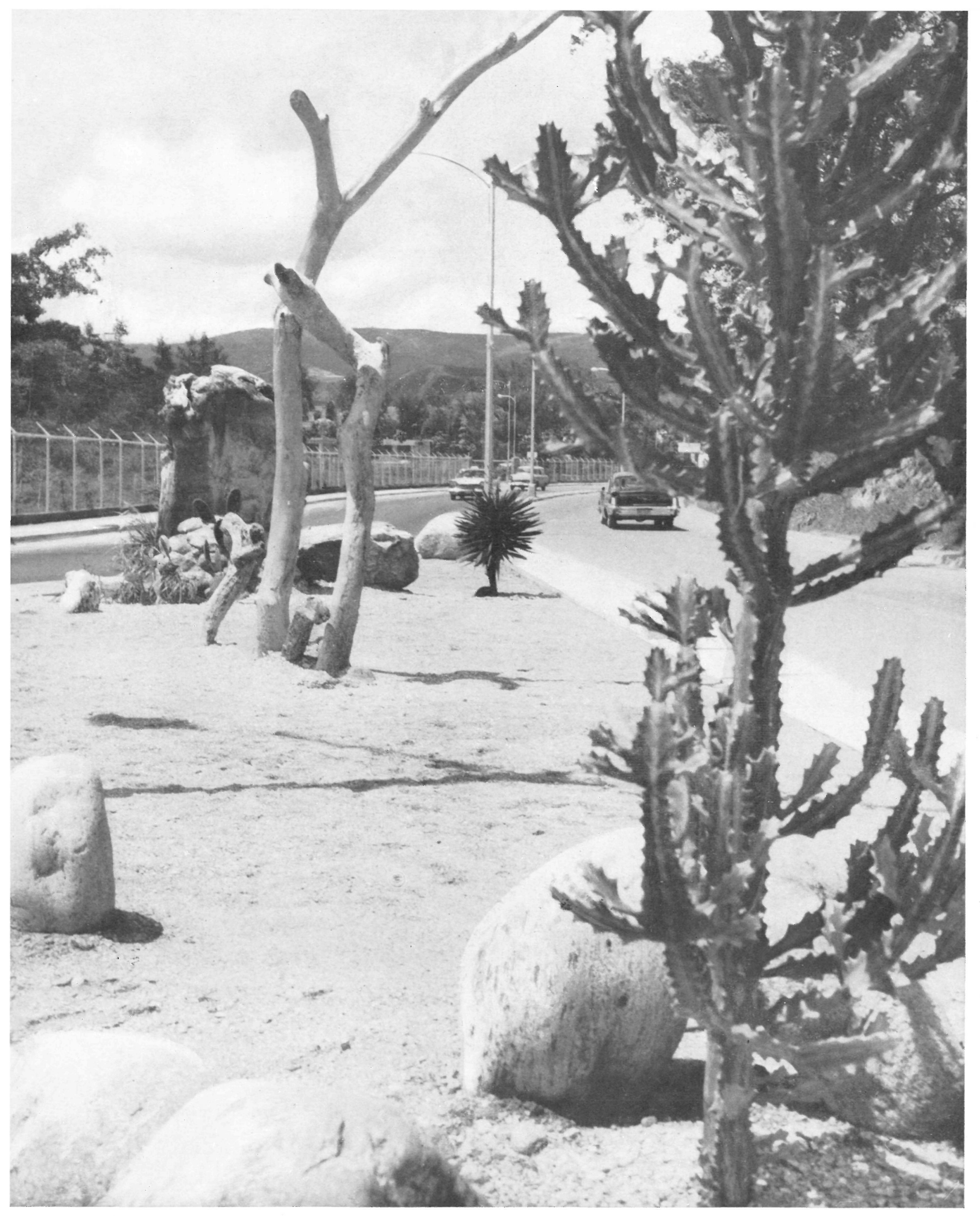

Se recogen en estas páginas una colección de jardines en que los elementos vegetales utilizados son, en su mayoría, plantas de las llamadas «xerófilas» (del griego xeros, seco), debido a que son propias de ambientes de bajo coeficiente de humedad, por lo cual el tejido epidérmico de defensa o protección del vegetal tiene sus células provistas de 

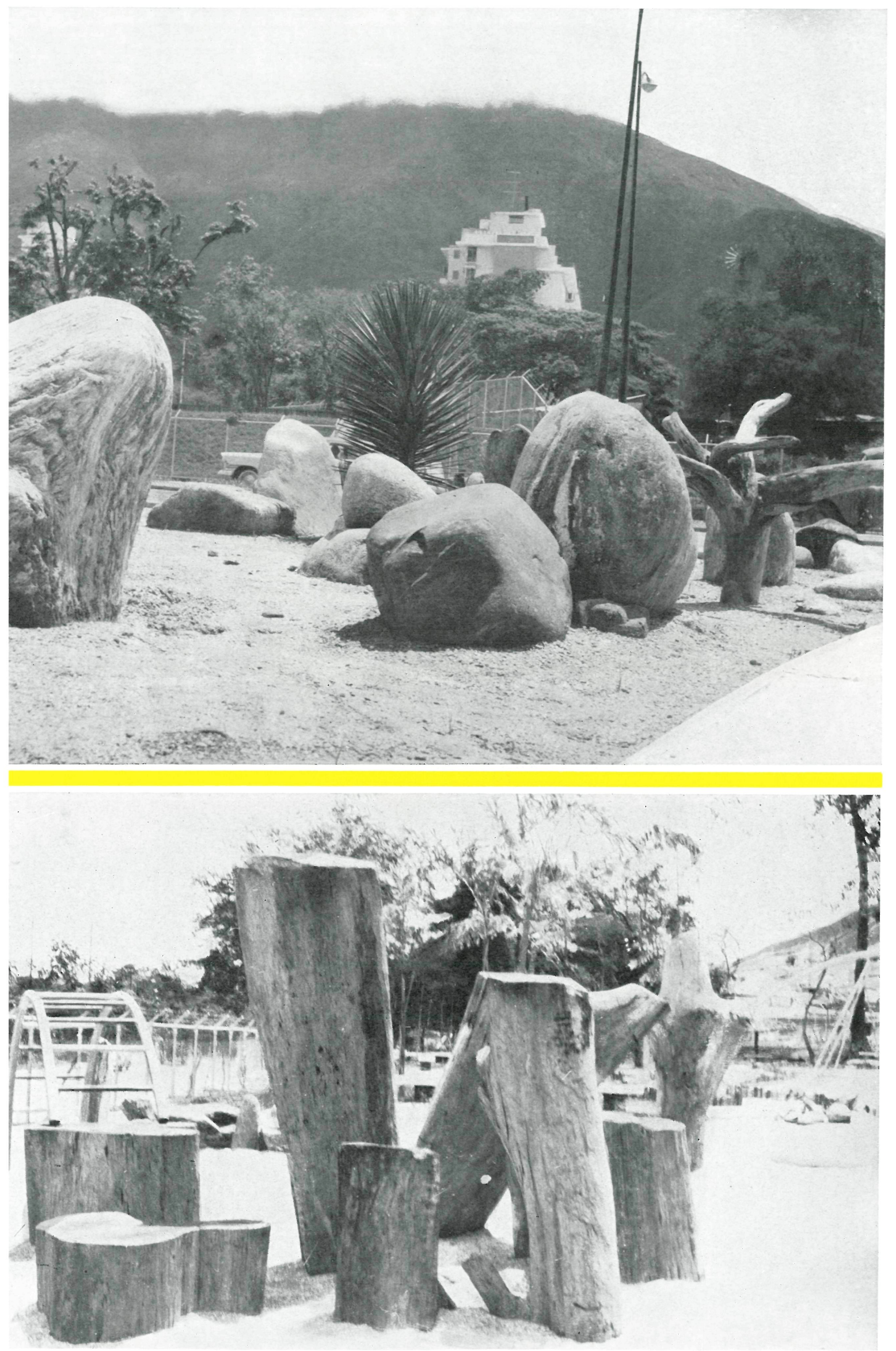


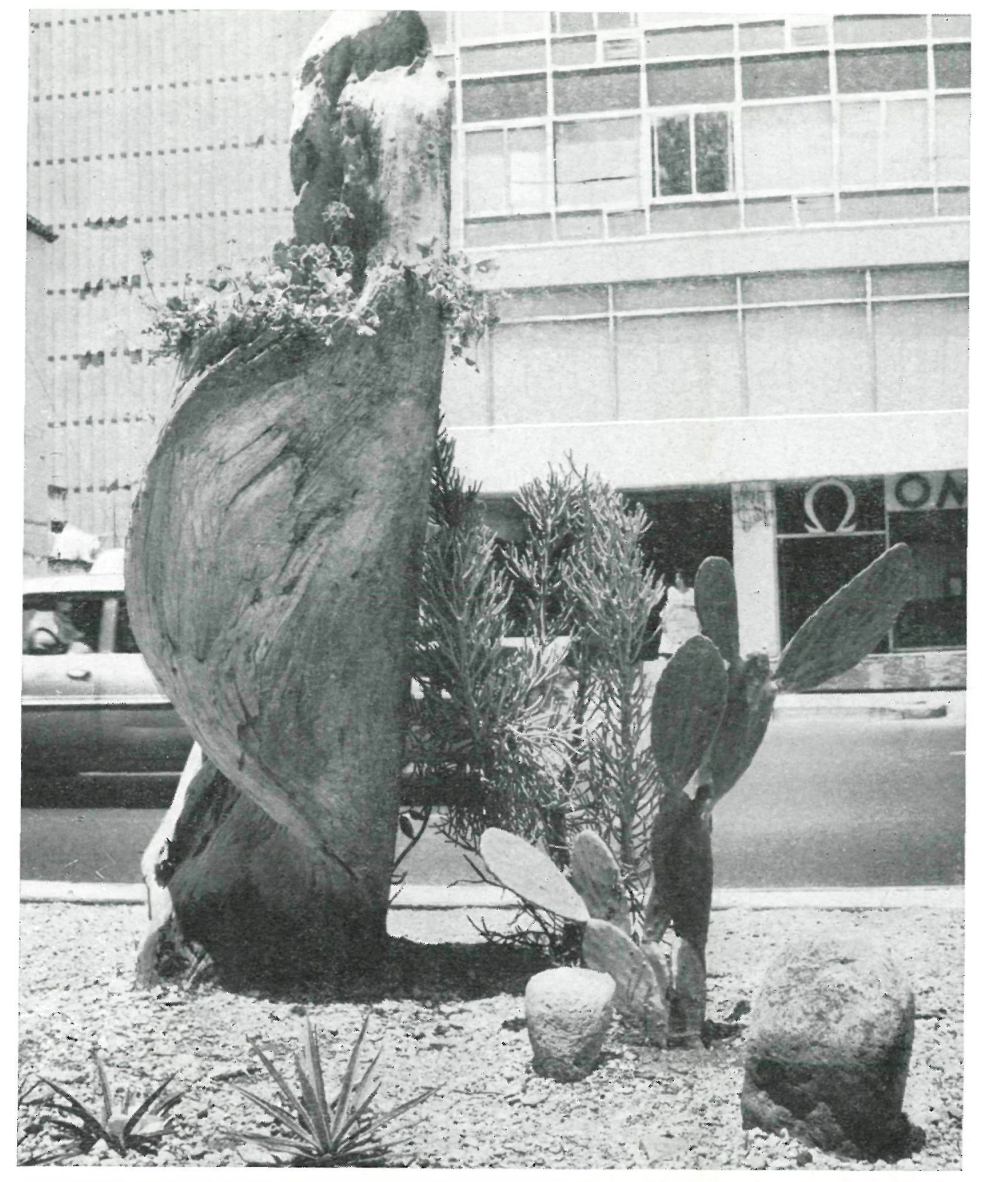

recia capa de cutina, con hojas - cuando existen- pequeñas, duras y coriáceas, pocos estomas (orificios de comunicación del exterior de la planta con el medio ambiente) y, frecuentemente, abundantes pelos protectores. De esta manera la evaporación de agua del vegetal resulta mínima y, como consecuencia, la necesidad de riego o de lluvia es insignificante, por alimentarse en épocas de sequía prácticamente con sus propias reservas almacenadas. Son generalmente de
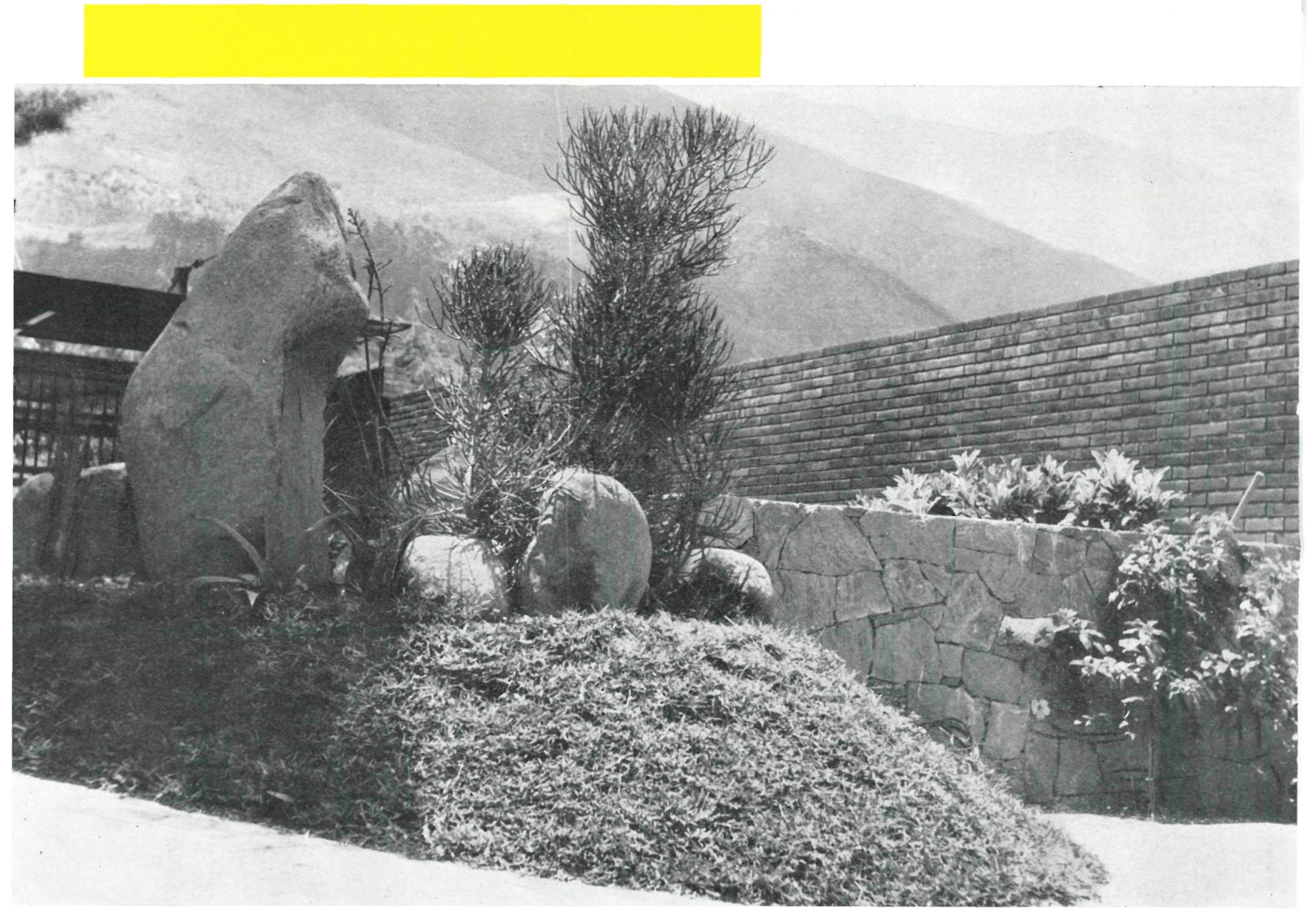
tallos recios y resistentes, de consistencia leñosa, que muchas veces se transforman en espinas o tienen aguijones. Entre ellas se encuentran las llamadas plantas carnosas, crasas o suculentas, como las cactáceas, crassuláceas y también algunas cuphorbiáceas, liliáceas y bromeliáceas.

Este tipo de jardines resulta apropiado para lugares como Caracas y otros aún más aridos, en los cuales el período de sequía -verano según la expresión usual- se prolonga durante bastantes meses del año y, además, el agua para riego artificial está restringida por razones diversas. Sin contar con que el mantenimiento de estas plantas exige menos cuidado en general que las de otras familias botánicas en cuanto a suelos, fumigación y aun podas formativas; y también en cuanto a vigilancia para defensa contra hurtos, ataques o maltratos por parte de seres vivos, puesto que la mayoría son casi silvestres y se defienden por sí mismas con sus espinas o su látex, que ofrece respeto y hasta peligro para el atacante. Con ellos se pueden conseguir zonas verdes bastante sugestivas, que estarán más frondosas y más verdes precisamente cuanto mayor es la sequía ambiente y peor y más triste aspecto presentan los jardines que se consideran normales.

Como una de las características de estos jardines es la ausencia de césped conseguido a base de cualquier especie gramínea, que no aguantaría la sequía y no podría vivir al mismo tiempo que las matas indicadas anteriormente, el piso suelto y arenoso propio para éstas se utiliza como fondo de la com- 
posición del jardín, recubriéndolo con piedra blanca de río o de mar y a veces con arena limpia. Con el ambiente semidesértico y un poco oriental que produce inicialmente la combinación de material y vegetales descrita, encaja el uso de cantos o piedras rodadas de río y de mar de tamaños diversos, desde el indicado arrocillo redondeado hasta la piedra con textura escultórica o cerámica, que podría firmar un escultor de fama. Y se integran bien en el conjunto, sirviendo de base y sostén a los arbustos, los también escultóricos troncos que el mar arroja a las playas venezolanas del litoral caribeño, donde el sol y la sal los curan y calcinan después de ser moldeados por las olas durante años en la ida y venida de las mareas. Tallas naturales en madera que el arquitecto utiliza con sentido encontrista e informalista, sin pintarlos ni variarlos de forma ni textura, en su inerte vitalidad, componiéndolos con los demás elementos naturales, minerales y vegetales, en alturas, superficies y colores. Todo ello con criterio de simplicidad abstracta que teme al barroquismo y que sabe - como saben los japoneses de hoy y de siempre-que en toda obra de creación, por muy modesta que sea, lo difícil es determinar, no lo que se pone, sino lo que no se debe poner; lo que es esencial y lo que resulta superfluo.

La simplicidad no es punto de partida, sino de llegada. No es mejor jardín el que contiene más plantas, sino el que las luce en el debido lugar; y un jardín con matas mal cuidadas o instaladas incómodamente y sin orden ni concierto, es solamente un manicomio o una prisión de plantas. 

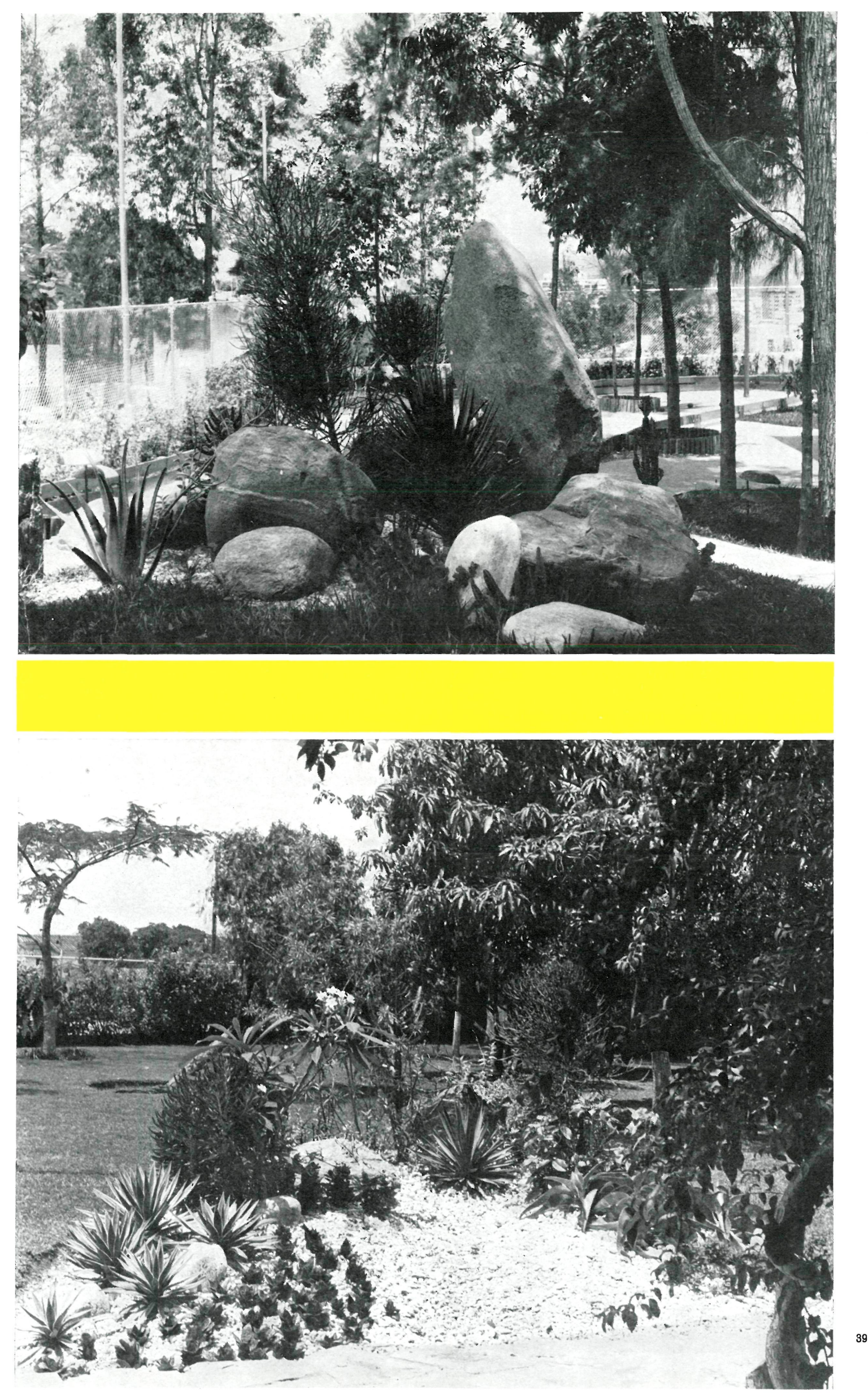


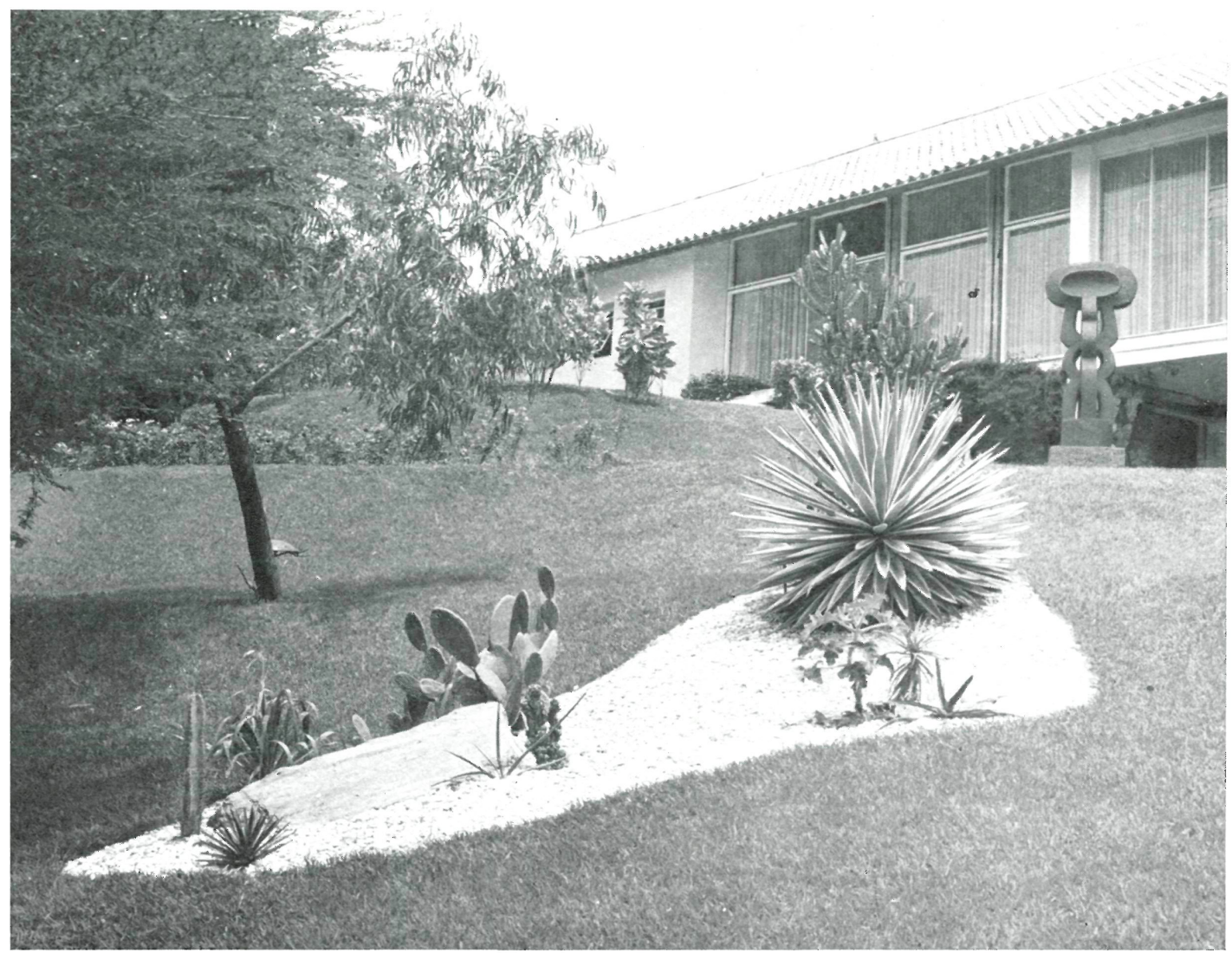

Por último, es conveniente recordar que un jardín, en que no existen sólo muros, arena, piedras y troncos, sino también plantas vivas, no está terminado hasta que se convierte en realidad y toma su forma la composición ideada. Que las plantas no basta con que afiancen sus raíces en el suelo y den fe de vida en su nueva ubicación, pues habrá que esperar para ver el jardín a que árboles, arbustos y matas alcancen el desarrollo previsto en la imaginación del arquitecto paisajista que lo proyectó.
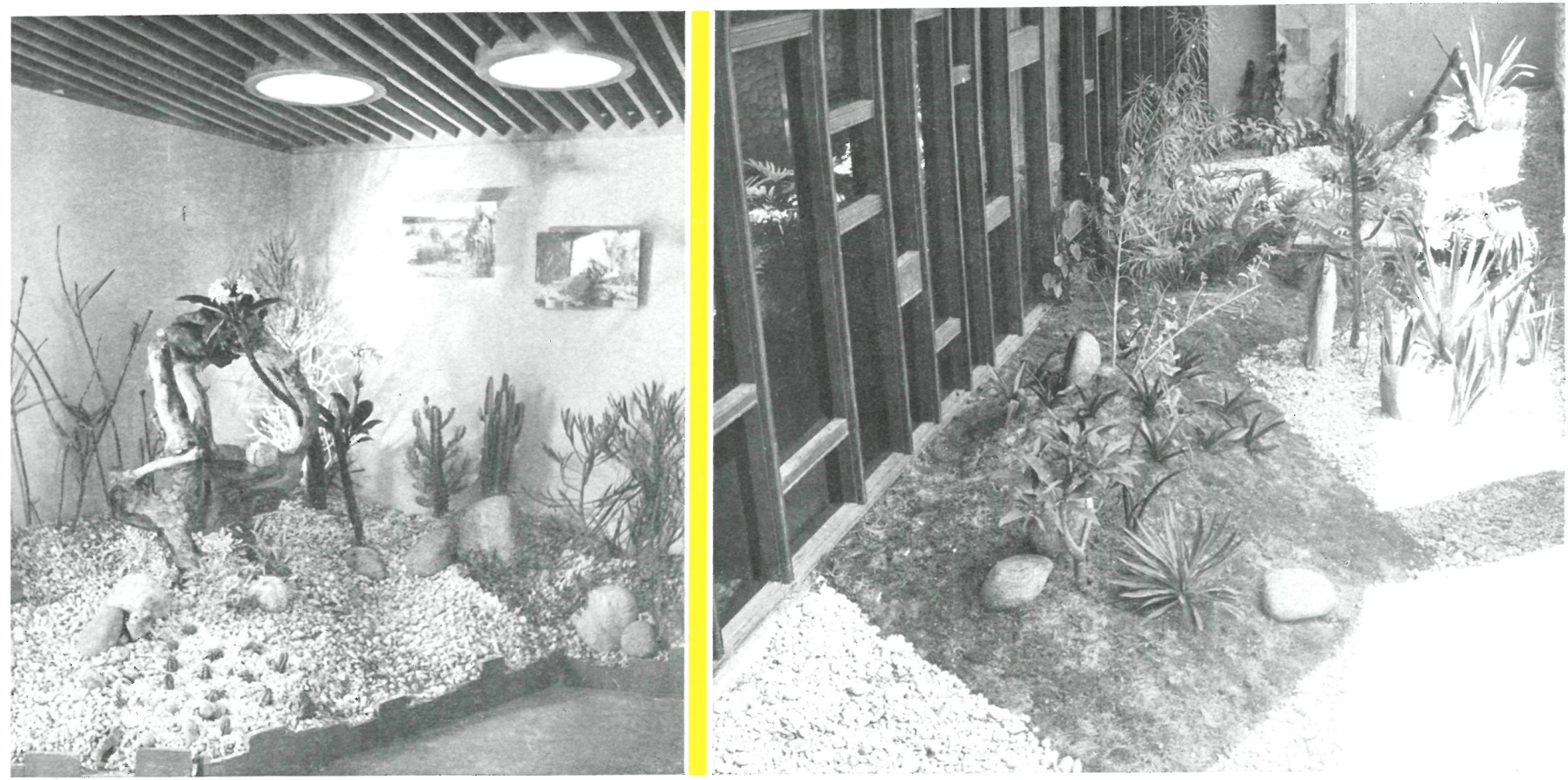


\section{Jardins xémoplhilles vémézuéliens}

Eduardo Robles Piquer, architecte-paysagiste

Ce type de jardins -à base de plantes xérophiles, propres aux climats secs, dont l'évaporation d'eau végétale est minimale et, par conséquent, le besoin d'irrigation ou de pluie insignifiant- résulte parfaitement approprié pour des régions comme Caracas et d'autres encore plus sèches et plus arides.

Une des caractéristiques de ces jardins est l'absence de gazon, le type sableux utilisé comme fond de la composition, recouvert par des galets blancs de rivière ou de mer et, parfois, uniquement, par du sable propre.

Les différences de hauteurs des plantes, de surfaces et de couleurs, et l'intégration à l'ensemble des éléments minéraux - galets-, des végétaux - troncs, etc.-, contribuent à rehausser la beauté de ces jardins.

\section{Dry climate gardedens in Vemezuela}

Eduardo Robles Piquer, landscape architect

This type of gardens, consisting of plants that are suitable for dry climates, and where the water evaporation from the plants is minimal, and thus need an insignificant amount of watering or rainfall, is most appropriate for places such as Caracas, and other even drier zones, where the drought period is very prolonged each year.

As one of the characteristics of these gardens is the absence of grass, loose sandy soil is utilised as the base material of the garden, and this is covered with white river pebbles, and sometimes with clean sand.

The varying heights of the plants, their surfaces and colours, and the integration of the mineral elements, such as pebbles, and the plants themselves, help to heighten the charm and beauty of these gardens.

\section{Venezolumische Duerppfinmzem - Gaertem}

Eduardo Robles Piquer, Gartenarchitekt

Diese Art von Gaerten - aufgrund von fuer einte trockene Umgebung geeigneten Duerrpflanzen, bei denen die Pflanzenwasserverdunstung sehr gering und der Bedarf an Bewaesserung oder Regen daher unbedeuten ist - ist sehr geeignet fuer Orte wie Caracas und selbst fuer trockenere, in welchen die jaehrliche Trockenzeit monatelang dauert.

Da eines der Merkmale dieser Gaerten darin besteht, dass keine Rasenflaechen vorgesehen sind, wird die Unterlage der Gartenkomposition locker und sandig gehalten und mit weissen Fluss- oder Meersteinen belegt und manchmal mit reinem Sand.

Die verschiedenen Hoehen der Pflanzen, Flaechen und Farben und die Eingliederung ins Ganze von Elementen mineralischer - Rollsteine- und pflanzlicher Natur -Baumstaemme, usw.- tragen zur Erhoehung der Schoenheit dieser Gaerten bei. 